\title{
Infection-related complications in patients with end-stage renal failure dialyzed through a permanent catheter
}

\author{
Anna Szarnecka-Sojda', Wojciech Jacheć ${ }^{2,3}$, Maciej Polewczyk ${ }^{4,5}$, \\ Agnieszka Łętek ${ }^{4,6}$, Jarosław Miszczuk', Anna Polewczyk ${ }^{4,6}$ \\ 'Vascular Surgery Clinic, Provincial Hospital, Kielce, Poland \\ ${ }^{2} 2^{\text {nd }}$ Department of Cardiology, Medical University of Silesia in Katowice, Poland \\ ${ }^{3}$ School of Medicine with the Division of Dentistry in Zabrze, Poland \\ ${ }^{4}$ Faculty of Medicine and Health Studies, Jan Kochanowski University, Kielce, Poland; \\ ${ }^{5}$ Swietokrzyskie Cardiology Center, Acute Cardiac Care Unit, Kielce Poland \\ ${ }^{6}$ Department of Cardiology, Swietokrzyskie Cardiology Centre, Kielce, Poland
}

\begin{abstract}
Introduction: Progression of renal failure leads to an increase in the number of patients who require forming dialysis access. Old age and rising morbidity make it impossible to form a native arteriovenous fistula and a permanent catheter becomes the first choice. The presence of a catheter frequently generates complications, including infections, which may result in a higher mortality rate.
\end{abstract}

Material and methods: A retrospective analysis data has been conducted, involving 398 patients who had permanent catheters implanted from 2010 to 2016. Out of this group, 65 patients who suffered infectionrelated complications have been identified. Risk factors for infection and a survival rate of the population have been estimated.

Results: Between 2010 and 2016, 495 catheters were implanted for 398 patients aged 68.73 (13.26) years on average. 92 catheter-related infections (23.1\%) were recorded in 65 patients. Multivariate logistic regression showed, that the risk factors of infectious complications were: younger age $(P=0.000)$, coronary artery disease $(P=0.006)$ and heart failure $(P=0.000)$. Mortality in the mean $1.38 \pm 1.17$ years followup period was comparable in infectious and non-infectious subgroups (53.85\% vs $49.25 \%$; $P=0.588$ ). A higher risk of death in the infectious population was associated with the presence of additional intravascular and intracardiac implanted materials $(P=0.027)$ and a severe course of infection with hypotension $(P=0.027)$, thrombocytopenia $(P=0.029)$ and a high leucocytes/platelets ratio $(0.017)$.

Conclusion: Infectious complications in patients dialyzed with permanent catheters are dangerous especially in patients with severe clinical course. The mortality rate is high, although similar to all dialyzed by permanent catheters.

Key words: end-stage renal disease, permanent dialysis catheter, infectious complications, death risk

Acta Angiol 2020; 26, I: 9-18

\section{Introduction}

The end-stage renal disease leads to an increasing number of patients who require dialysis therapy and kidney transplant. In Poland, approximately 4.5 million people suffer from chronic kidney disease and 21,043 patients receive renal replacement therapy $[I, 2]$. Aging of the population and high morbidity of this group of patients 
makes it difficult to create a native arteriovenous fistula, still called the gold standard of vascular access. Dialysis often starts with a permanent catheter inserted into the venous system and its long-term use is limited by a high risk of infection and death [2,3]. Dialysis patients are a group particularly vulnerable to infections, mostly those spreading through the bloodstream. This exposure is largely associated with the presence of infection entry via vascular access to dialysis. In addition, the development of end-stage renal disease (ESRD) is more common in patients with comorbidities: diabetes, hypertension, atherosclerosis. The course of uremia leads to further dysfunction of many organs and systems. Dialysis treatment makes it possible to remove uremic toxins and to balance water and electrolytes, but not completely. This results in permanent suppression of the immune system with greater exposure to infectious complications.

Infectious complications are one of the most common reasons for the loss of catheter function. Infections related to vascular access account for $50-80 \%$ of all infections that occur in this patient group, and they lead to the death of $10 \%$ of dialyzed patients $[1,4]$.

The aim of this study was to identify risk factors of infection-related complications and death risk in a group of patients who were dialyzed through permanent catheters over a period of seven years' observation.

\section{Material and methods}

The information obtained from the National Health Fund (NFZ) provided clinical data for a retrospective analysis of 398 patients from the Świętokrzyskie Province who had their first permanent catheter inserted from I January 2010 to 31 December 2016. Out of this group, 65 patients who suffered 92 infection-related complications were identified, and risk factors for infection and death of these patients were estimated. The study considered impact of the following clinical factors on infection-related complications: arterial hypertension, coronary disease, atrial fibrillation, heart failure, generalized atherosclerosis, diabetes, history of stroke, neoplastic disease, chronic obstructive pulmonary disease, presence of cardiac implants (cardiac implantable electronic device-CIED, artificial valves, biomaterials for vascular prosthetic devices implanted in aorta and peripheral vessels), and venous thrombosis.

Catheter-related infections were diagnosed according to the criteria worked out by American and European Centres of Prevention and Disease Control (HAl: Healthcare Associated Infection, CDC: Centers for Disease Control and Prevention; ECDC: European Centers for Disease Control and Prevention) $[5,6,7]$. Infectious complications were divided into infections of a catheter insertion site, infection of a catheter tunnel, bacteraemia accompanied by high temperature, shaking chills, hypotension and rising inflammatory parameters. Catheter Related Bloodstream Infection (CRBSI) was defined as an infection of the vascular bed occurred within 48 hours from inserting or removing a catheter with positive blood culture and isolating the same microorganism from peripheral blood and from pus from the catheter insertion site. Growth in quantitative culture from a catheter tip must be $>10^{3} \mathrm{CFU} / \mathrm{ml}$ and the number of CFU microorganisms should be five times as high as peripheral blood. Detection time of samples taken in an automatic system exceeds 2 hours and a sample taken from a catheter is marked positive earlier than is the case for a sample of peripheral blood.

Central Line-Associated Bloodstream Infection (CLABSI) was defined as an infection in a patient with a central catheter when blood culture is positive while catheter site culture is negative [5, 7-9].

Based on the analysis of available medical records of 47 patients out of 65 subjects with infectious complications, a precise assessment of the influence of procedural factors on the development of infection was performed. For this group of 47 patients the following data were also analysed: reasons for catheter insertion and removal, reasons for subsequent hospitalizations after its insertion, a number of catheters implanted for one person, total and average functioning time of one catheter and the functioning times of the catheter inserted after a dialysis fistula, time from catheter insertion to the onset infection, location of venous access and location of a catheter tip. A detailed analysis of the following data was also carried out: a course of infection-related complications, including the time of hospitalization, the occurrence of septicaemia, infective endocarditis, pneumonia, abscesses distant from vascular access site, kind of infection-inducing bacteria based on blood and catheter tip cultures as well as recurrence of infection. The analysis also involved values of biochemical tests and the impact of individual factors on a survival rate among patients affected by infection-related complications.

The study was approved by the Bioethics Committee of Świętokrzyska Medical Council: Resolution No $21 / 2017$.

\section{Statistical methods}

Distribution of all continuous variables was evaluated by the Shapiro-Wilk test. The continuous data were presented as mean with the standard deviation. Categorical data are presented as absolute numbers and percentage. Continuous variables were compared by Student's t-test and Mann-Whitney $U$ test, while chisquare test with Yates correction was used to compare dichotomous variables. 
Uni- and multivariable linear regression was used to determine risk factors of catheter infection

Only variables with a value of $P \leq 0.05$ at univariate analysis were included in the multivariate analysis.

Cumulative survival curves for all-cause death were constructed by the Kaplan-Meier methods. Survival curves were compared among groups with the logrank test.

The differences were found as statistically significant when $\mathrm{p}<0.05$.

\section{Results}

In the period from January 2010 to December 2016, 495 permanent catheters were implanted in 398 people (194 men,48.7\%) with a mean age of 68.73 (13.26) years. In the whole study group $(n=398)$ there were $92(23.1 \%)$ catheter-related infectious complications in $65(16.3 \%)$ patients. In 28 (6.1\%) patients repeated infections were observed.

More frequent infectious complications have been observed in patients with a longer dwell time of catheter(s) who needed catheter replacement, patients with thrombotic complications including stroke, generalized atherosclerosis, diabetes, arterial hypertension, chronic atrial fibrillation, coronary artery disease, heart failure, history of neoplastic disease and other comorbidities. During the mean I.38 (I.I7) years ( $\min 0.0$ max 6.70 years) follow-up 199 deaths occurred $(50.0 \%)$. There was no significant difference in survival between patients with infectious complications $(35,53.85 \%)$ and those without infectious complications (164, 49.25\%) (Table I).

The univariable analysis demonstrated that generalized atherosclerosis, diabetes, thrombotic catheter complications, neoplastic disease, atrial fibrillation, arterial hypertension, coronary artery disease, previous stroke, heart failure and co-existing diseases were risk factors of a catheter-related infection (CRI) (Table 2).

In the studied group of 398 people, there were 92 catheter related infectious complications in 65 patients. The mean infection rate was 0.46 per I,000 catheter days.

A detailed analysis of medical records of the separate subgroup of 47 patients with catheter related infectious complications identified 68 infections ( 13 patients suffered from repeated infections). The total functioning time of all catheters from insertion of the catheter to infection was 13,074 days, the time of the longest functioning catheter in this group was I, I08 days. The total time of hospitalization due to infectious complications for the group $(n=47)$ was 798 days, the average time of hospitalization was II.73 days. 6I hospitalized patients were treated successfully and discharged from the hospital while 7 patients died.
In the analyzed subgroup of 47 patients with infectious complications, 8 patients ( $11.76 \%$ ) developed pneumonia and $3(4.41 \%)$ had endocarditis. In 13 (19.11\%) cases, the infection required the removal of a permanent catheter.

A comparison of the location of the catheter tip in the superior vena cava and the inferior vena cava did not show an effect of the catheter placement on the incidence of infection $(p=0.68)$. Similarly, the duration of catheter functioning had no effect on the risk of infection in this group $(P=0.621)$. A comparison of the position of the catheter tip in the superior vena cava and the inferior vena cava did not show an effect of the position of the catheter on the occurrence of infection ( $P=0.68)$.

A detailed analysis of blood culture and catheter tip culture identified 42 (6I.77\%) cases of CRBSI, 22 $(32.35 \%)$ cases of bacteraemia with a negative blood culture and catheter culture qualified as CLABSI, and 4 cases $(5.88 \%)$ of local infection that required hospitalization, with a negative blood and catheter cultures, and those were mainly abscesses. Infection symptoms in a catheter insertion site were found in 25 (37.64\%) cases, in $16(23.53 \%)$ cases infection occurred together with implications of distant organs, including 8 (1 I.76\%) cases of pneumonia, $3(4.4 \mathrm{l} \%)$ cases of infective endocarditis and $5(7.35 \%)$ cases of distant skin infections. In $13(19.11 \%)$ cases, the infection required the removal of a permanent catheter.

Infection lesions in catheter insertion site ( 25 cases) co-existed in 18 cases with CRBSI, in 6 cases with CLABSI (with negative catheter cultures), and in I case, a positive catheter culture was not accompanied by general symptoms: it was an infection of the skin and a catheter tunnel only.

The study identified 68 infections in 47 dialysed patients; 39 (57.35\%) cases were caused by Grampositive bacteria, and 29 (42.64\%) by Gram-negative bacteria. Gram-positive infections were caused in $20(29.41 \%)$ by Staphylococcus aureus, and in $19(27.94 \%)$ cases by other staphylococci, mainly by Staphylococcus epidermidis. The most common Gram-negative pathogens were Klebsiella pneumoniae revealed in 8 (1 $1.76 \%)$ cases and Escherichia coli in $8(11.76 \%)$ cases. Summary of pathogens and their effect on the course of infection associated with the catheter in 68 infectious complications are shown in the (Table 4).

A detailed analysis of survival among 47 patients with infection-related complications showed a higher death risk among patients with cardiac implantable electronic devices (CIED) and biomaterials implanted in peripheral vessels. A worse prognosis was identified among patients with infection accompanied by 
Table I. Clinical data of patients dialyzed by permanent catheter and comparison of subgroups with and without catheter-related infections

\begin{tabular}{|c|c|c|c|c|}
\hline & $\begin{array}{l}\text { Patients with } \\
\text { permanent } \\
\text { catheters }\end{array}$ & $\begin{array}{l}\text { Patients with } \\
\text { catheter-related } \\
\text { infection }\end{array}$ & $\begin{array}{l}\text { Patients without } \\
\text { infective } \\
\text { complications }\end{array}$ & $\begin{array}{c}\text { P } \\
\text { Mann-Withney } \\
\text { "U" } / \chi^{2} \text { test }\end{array}$ \\
\hline Number (n, \%) & $398(100.0 \%)$ & $65(100.0 \%)$ & $333(100.0 \%)$ & \\
\hline Age [years] mean \pm SD & $68.73(13.26)$ & $66.04(13.20)$ & $69.26(13.23)$ & $P=0.073$ \\
\hline Male (n, \%) & $194(48.74 \%)$ & $36(55.38 \%)$ & 158 (47.45\%) & $P=0.301$ \\
\hline $\begin{array}{l}\text { No of catheters inserted after } \\
\text { failure of previously created } \\
\text { dialysis fistula }(n, \%)\end{array}$ & $129(32.41 \%)$ & $26(40.00 \%)$ & 103 (30.93\%) & $P=0.199$ \\
\hline $\begin{array}{l}\text { Dwell times of dialysis } \\
\text { catheter(s) [days] mean } \pm \text { SD }\end{array}$ & $505.2(428.3)$ & $548.3(449.0)$ & $496.7(424.3)$ & $P=0.347$ \\
\hline $\begin{array}{l}\text { Average time of catheter } \\
\text { usability (days; SD) }\end{array}$ & $435.7(398.2)$ & $419.4(392.1)$ & $438.9(399.9)$ & $P=0.718$ \\
\hline $\begin{array}{l}\text { No of patients with single } \\
\text { catheter }(n, \%)\end{array}$ & $322(80.90 \%)$ & $4 \mathrm{I}(63.08 \%)$ & $28 \mathrm{I}(84.38 \%)$ & $P=0.0001$ \\
\hline $\begin{array}{l}\text { No of patients with one } \\
\text { catheter replacement }(n, \%)\end{array}$ & 58 (14.57\%) & $15(23.08 \%)$ & $43(12.91 \%)$ & $P=0.053$ \\
\hline $\begin{array}{l}\text { No of patients with two } \\
\text { catheter replacements (n, \%) }\end{array}$ & $16(4.02 \%)$ & $8(12.31 \%)$ & $8(2.40 \%)$ & $P=0.0007$ \\
\hline $\begin{array}{l}\text { Venous thrombotic } \\
\text { complications }(n, \%)^{a}\end{array}$ & $66(16.58 \%)$ & 18 (27.69\%) & $48(14.41 \%)$ & $P=0.014$ \\
\hline $\begin{array}{l}\text { Generalized atherosclerosis } \\
(\mathrm{n}, \%)^{\mathrm{b}}\end{array}$ & 108 (27.14\%) & $33(50.77 \%)$ & 75 (22.52\%) & $P=0.000$ \\
\hline Diabetes (n, \%) & $73(18.34 \%)$ & $21(32.31 \%)$ & $52(15.62 \%)$ & $P=0.003$ \\
\hline Arterial hypertension (n, \%) & $109(27.39 \%)$ & $35(53.85 \%)$ & $74(22.22 \%)$ & $P=0.000$ \\
\hline Coronary disease (n, \%) & $44(11.06 \%)$ & $22(33.85 \%)$ & $22(6.61 \%)$ & $P=0.000$ \\
\hline Atrial fibrillation (n, \%) & $12(3.02 \%)$ & $7(10.77 \%)$ & $5(1.50 \%)$ & $P=0.000$ \\
\hline Heart failure (n, \%) & $78(19.60 \%)$ & 37 (56.92\%) & $41(12.31 \%)$ & $P=0.000$ \\
\hline Past history of stroke (n, \%) & $4(1.01 \%)$ & $3(4.62 \%)$ & I (0.30\%) & $P=0.012$ \\
\hline $\begin{array}{l}\text { History of neoplastic disease } \\
(\mathrm{n}, \%)\end{array}$ & $78(19.60 \%)$ & $21(32.31 \%)$ & $57(17.12 \%)$ & $P<0.008$ \\
\hline Co-existing diseases $(n, \%)^{c}$ & $87(21.86 \%)$ & $22(33.85 \%)$ & $65(19.52 \%)$ & $P<0.017$ \\
\hline Death during follow-up (n, \%) & 199 (50\%) & $35(53,85)$ & $164(49,25 \%)$ & $P=0.588$ \\
\hline
\end{tabular}

No: number; SD: standard deviation; av: average; NS: no statistically significant difference.

ahistory of venous thromboembolism

batherosclerosis diagnosed at least in two locations

co-existing diseases affecting the patients studied, not analysed individually, marked with the following codes the International Statistical Classification of Diseases and

Related Health Problems — ICD-IO: D 50; D53; D64; E03; E04 E27; G65 J20; J42; J44; J45; J 81; J 96; K26; K50; K65; K76; L08; L97; M06; M 32; M 34; S68

hypotension, high leucocytosis, a lower level of blood platelets and a high leucocytes/blood platelets (WBC/ /PLT) ratio. Present study showed that a type of bacteria Gram (+) or Gram (-) had no effect of the higher death risk (Table 5).

Univariable regression analysis shown that the following factors contributed to higher risk of death: presence of cardiac implants and a severe course of infection with hypotension, high leucocytosis, thrombocytopenia and a high WBC/PLT ratio (Table 6).

\section{Discussion}

Permanent catheters are an option for patients requiring hemodialysis for whom the formation of a fistula from own vessels is impossible or contraindicated. Dialysis through a tunnelled catheter may lead to numerous dangerous consequences. Catheter-related infection occur $41 \%$ more frequently than is the case among patients with native A-V fistula [10-12]. According to National Kidney Foundation patients with 
Table 2. Risk factors of $\mathrm{CRI}$ - results of univariable linear regression analysis

\begin{tabular}{|l|c|c|c|}
\hline Infection-related complications & OR & $95 \%$ C & P-value \\
\hline Patient's age & 0.983 & $0.964-1.002$ & 0.076 \\
\hline Generalized atherosclerosis & 3.548 & $2.043-6.159$ & 0.000 \\
\hline Diabetes & 2.579 & $1.415-4.699$ & 0.002 \\
\hline Venous thrombotic complications & 2.274 & $1.217-4.250$ & 0.010 \\
\hline Neoplastic disease & 2.311 & $1.275-4.189$ & 0.006 \\
\hline Atrial fibrillation & 7.917 & $2.421-25.888$ & 0.001 \\
\hline Arterial hypertension & 4.083 & $2.348-7.103$ & 0.000 \\
\hline Coronary artery disease & 7.233 & $3.688-14.185$ & 0.000 \\
\hline Heart failure & 9.411 & $5.208-17.005$ & 0.000 \\
\hline Co-existing diseases & 2.109 & $1.178-3.777$ & 0.012 \\
\hline
\end{tabular}

The multivariable linear regression analysis has shown that independent risk factors of CRI were: younger age of patients, the presence of coronary artery disease and heart failure (Table 3); OR: odds ratio, Cl: confidence inteval

Table 3. The risk factors of CRI — results of multivariable linear regression analysis

\begin{tabular}{|l|c|c|c|}
\hline Infection-related complications & OR & $95 \%$ CI & P-value \\
\hline Patient's age & 0.955 & $0.931-0.979$ & 0.000 \\
\hline Generalized atherosclerosis & 1.859 & $0.751-4.598$ & 0.178 \\
\hline Diabetes & 0.783 & $0.352-1.745$ & 0.549 \\
\hline Thrombotic complications & 1.429 & $0.661-3.092$ & 0.363 \\
\hline Neoplastic disease & 1.556 & $0.751-3.225$ & 0.233 \\
\hline Co-existing diseases & 1.320 & $0.643-2.710$ & 0.448 \\
\hline Atrial fibrillation & 1.923 & $0.414-8.920$ & 0.402 \\
\hline Arterial hypertension & 1.840 & $0.909-3.725$ & 0.089 \\
\hline Coronary artery disease & 3.412 & $1.423-8.179$ & 0.006 \\
\hline Heart failure & 4.532 & $2.013-10.202$ & 0.000 \\
\hline
\end{tabular}

OR: odds ratio; $\mathrm{Cl}$ : confidence inteval

a catheter run the twice as high risk as those using A-V fistula $[5,8]$, and the BSI (bloodstream infection) rate is 4.85 times as high when tunnelled catheters are used [ $\mathrm{I} \mathrm{I}]$. The present study identified 92 (23.1\%) catheterrelated infection of an average infection rate of 0.46 per I,000 catheter days. In case of tunnelled catheters, according to various sources, the frequency of infectious complications ranges from 0.5 to 5.5 per $\mathrm{I}, 000$ catheter days [ II-I5]. The large discrepancy of results is probably related to the diversity of the studied populations and the research methodology. Long-term observation of a large group of patients in whom 2,230 permanent catheters were implanted during 23 years showed 226 infectious complications, with an infection rate of 0.514 per 1000 catheter days [16]. In another study, which analysed various types of vascular access over 6 years, the infection rate for permanent catheters was 1.03 per I,000 patient days [I I]. The next investigation, assessed the impact of the availability of specialist nephrological care on the risk of infection demonstrated
0.19 infections per 1000 catheter days [15]. According to a systematic overview of 200 prospective studies, an average $\mathrm{BSI}$ rate for tunnelled catheters amounted to I.6 per I,000 catheter days [17], while in the latest reports of 2019 , this rate was estimated at 2.26 per I,000 catheter days [13].

The present study showed that catheter-related infection occurred more often in a younger age and in patients with coronary artery disease and heart failure. One study comparing the risk of infection in younger patients (18-74 years old) dialyzed by a permanent catheter with a group of elderly patients (over 75 years) also demonstrated a higher infection risk among the younger patients ( 1.95 per 1,000 catheter days) than the older ones ( 0.55 per 1,000 catheter days) [18]. Other data regarding the impact of various factors on the occurrence of catheterrelated infections are not uniform due to the variety of parameters assessed. Most often the effect of diabetes is emphasized, which in the current study 


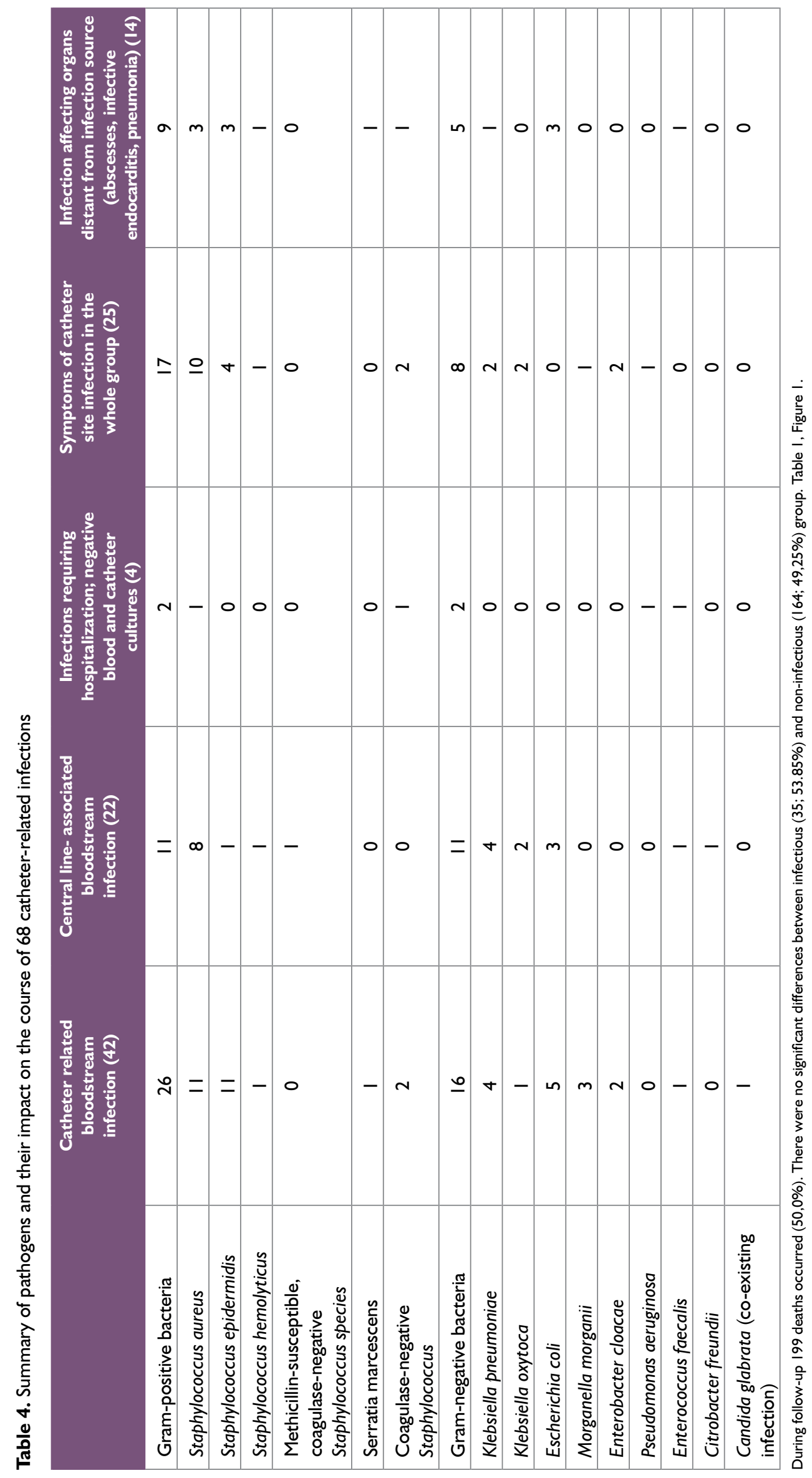




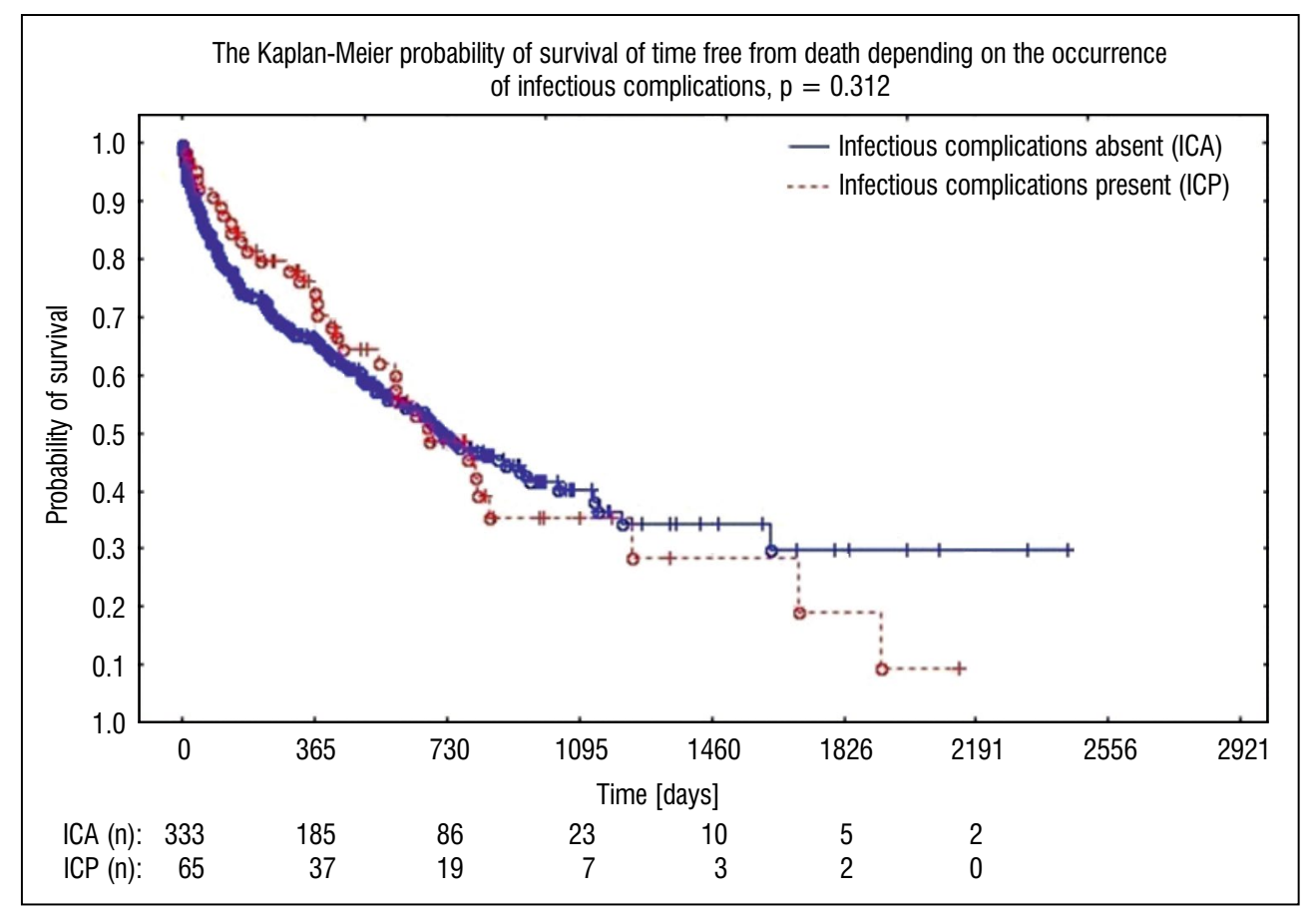

Figure I. Kaplan Meier time free of death in groups of patients divided depending on dialysis catheter infection presence

was an important risk factor in univariable analysis. A large group of patients dialyzed with permanent catheters showed that the risk factors for infectious complications were: prior bacteraemia, diabetes mellitus, time from catheter implantation $>90$ days, and hypertension [16]. Risk factors identified by another report included diabetes, generalized atherosclerosis, history of bacteraemia and carrying Staphylococcus aureus in the nasal cavity if coupled with long-term use of a catheter [13]. Other observation which involved 102 patients with 42 catheterrelated infections also identified diabetes, a low level of albumins and haemoglobin as factors contributing to infection-related complications [II]. In turn, a recent analysis of early catheter infection found an essential role of carrying MRSA (methicillin resistant) Staphylococcus aureus, previous catheter-related infection and bacteraemia or bacteriuria occurring up to 3 months before catheter insertion $[1,6,13]$.

In most cases, Gram-positive bacteria are responsible for infection among dialyzed patients: it is reported that they caused up to $75 \%$ catheter-related infections $[6,7,13,19,20]$, with two pathogens being the most frequent: Staphylococcus epidermidis (35\%) and Staphylococcus aureus (35\%). Gram-negative pathogens were found in up to $40 \%$ of cases [5, 6, 9, 17, 21, 22]. Our results showed similar proportions: $57.35 \%$ of infections were caused by Gram-positive bacteria, including Staphylococcus aureus (29.41\%) and other Staphylococci (27.94\%), mainly by Staphylococcus epi- dermidis. Infections caused by Gram-negative bacteria accounted for $42.64 \%$.

Blood infection due to vascular access is a serious challenge both in terms of diagnosis and therapy, which is especially noticeable in intensive care units, where it accounts for about $20-40 \%$ of all hospital infections [22-24]. The current study confirmed a low probability of survival of patients with infectious complications $(53,85 \%)$ during the follow-up period, however, it was comparable to the high mortality rate of dialyzed patients without infection (49.25\%; $P=0,588)$. The apparent lack of significant influence of infection on the survival of this group of patients is probably associated with the strong impact of other known risk factors for death in patients with renal failure: premature atherosclerosis and associated metabolic disorders.

The mortality rate among dialysis patients depends on the type of vascular access and is higher in patients with catheters and fistulas made of artificial materials [ 1 , $4,17,22,24-27]$. Paradoxically, progress in medicine has led to an increase in infection rate by introducing artificial materials to build new vascular access. One study which analysed a large population of 2,666 patients dialyzed by catheters showed $32 \%$ mortality rate over the period of observation. The study showed that patients with tunnelled catheters had 6.9-fold higher mortality from sepsis compared to patients dialyzed with A-V fistula [28]. The results of our study showed that the following factors contributed to the higher risk of death: the presence of heart and vessels implants and 
Table 5. Factors affecting survival among patients dialyzed through permanent catheters and suffering infection-related complications

\begin{tabular}{|c|c|c|c|}
\hline Infection-related complications & Death & Survivors & $\begin{array}{c}\text { P } \\
\text { Mann-Withney } \\
\text { "U" } / \chi^{2} \text { test }\end{array}$ \\
\hline No of patients (n, \%) & $7(14.9 \%)$ & $40(85.1 \%)$ & - \\
\hline Average age (years, SD) & $73.579(6.80)$ & $66.55(|4.4|)$ & 0.174 \\
\hline Female patients (n, \%) & $4(57.14 \%)$ & $23(57.50 \%)$ & 0.692 \\
\hline Hospitalization time (days, SD) & $12.57(6.63)$ & $13.40(9.94)$ & 0.756 \\
\hline Time from catheter insertion to infection occurrence (months, SD) & $8.62(8.80)$ & $3.97(4.21)$ & 0.124 \\
\hline Generalized atherosclerosis (n, \%) & $7(100 \%)$ & $25(62.50 \%)$ & 0.128 \\
\hline Diabetes (n, \%) & $2(28.57 \%)$ & $17(42.50 \%)$ & 0.783 \\
\hline Thrombotic complications (n, \%) & $0(0.00 \%)$ & $5(12.50 \%)$ & 0.745 \\
\hline Infection-related complications over the last 6 months (n, \%) & $5(71.43 \%)$ & $23(57.50 \%)$ & 0.783 \\
\hline Neoplastic disease (n, \%) & $3(42.86 \%)$ & $13(32.50 \%)$ & 0.919 \\
\hline COPD (n, \%) & $\mathrm{I}(14.29 \%)$ & $3(7.50 \%)$ & 0.888 \\
\hline Atrial fibrillation (n, \%) & $3(42.86 \%)$ & $5(12.50 \%)$ & 0.154 \\
\hline Arterial hypertension (n, \%) & $6(85.71 \%)$ & $29(72.50 \%)$ & 0.787 \\
\hline Coronary artery disease (n, \%) & $5(71.43 \%)$ & $18(37.50 \%)$ & 0.379 \\
\hline NYHA class I-II (n, \%) & $2(28,57 \%)$ & $22(55,00 \%)$ & 0.379 \\
\hline NYHA class III-IV (n, \%) & $5(71.43 \%)$ & $17(42.50 \%)$ & 0.315 \\
\hline Stroke (n, \%) & $0(0.00 \%)$ & $4(10.00 \%)$ & 0.888 \\
\hline Cardiac implants (n, \%) & $5(71.43 \%)$ & $10(25.00 \%)$ & 0.046 \\
\hline Positive catheter culture $(\mathrm{n}, \%)$ & $6(85.71 \%)$ & $28(70.00 \%)$ & 0.690 \\
\hline Local symptoms of infection (n, \%) & I (I4.29\%) & $15(37.50 \%)$ & 0.445 \\
\hline Positive blood culture (n, \%) & $7(100 \%)$ & $38(95.00 \%)$ & 0.682 \\
\hline Positive blood culture, Gram-positive bacteria (n, \%) & $4(57.14 \%)$ & $19(47.50 \%)$ & 0.951 \\
\hline Positive blood culture, Gram-negative bacteria (n, \%) & $3(42.86 \%)$ & $21(52.50 \%)$ & 0.951 \\
\hline Systemic symptoms of infection (n, \%) & $7(100 \%)$ & $36(90.00 \%)$ & 0.888 \\
\hline Pneumonia $(\mathrm{n}, \%)$ & $2(28.57 \%)$ & $4(10.00 \%)$ & 0.457 \\
\hline Infective endocarditis (n, \%) & $0(0.00 \%)$ & $2(5.00 \%)$ & 0.682 \\
\hline Hypotension (n, \%) & $5(71.43 \%)$ & $10(25.00 \%)$ & 0.046 \\
\hline Patients with recurring infection-related complications ( $\mathrm{n}, \%)$ & $\mathrm{I}(14.29 \%)$ & $12(30.00 \%)$ & 0.690 \\
\hline Venous access: right angle (n, \%) & $2(28.57 \%)$ & $25(62.50 \%)$ & 0.208 \\
\hline Venous access: left angle (n, \%) & $2(28.57 \%)$ & $7(17.50 \%)$ & 0.868 \\
\hline Venous access: left subclavian vein $(n, \%)$ & $2(28.57 \%)$ & $\mathrm{I}(2.50 \%)$ & 0.078 \\
\hline Venous access: right subclavian vein $(\mathrm{n}, \%)$ & $0(0.00 \%)$ & $2(5.00 \%)$ & 0.682 \\
\hline Venous access: left femoral vein (n, \%) & $0(0.00 \%)$ & $0(0.00 \%)$ & - \\
\hline Venous access: right femoral vein $(n, \%)$ & I (14.29\%) & $3(7.50 \%)$ & 0.888 \\
\hline Catheter tip location: superior vena cava $(\mathrm{n}, \%)$ & $6(85.71 \%)$ & $35(87.50 \%)$ & 0.629 \\
\hline Catheter tip location: inferior vena cava (n, \%) & I (I4.29\%) & $4(10.00 \%)$ & 0.745 \\
\hline Catheter removal due to infection $(\mathrm{n}, \%)$ & $3(42.86 \%)$ & $8(20.00 \%)$ & 0.404 \\
\hline Patients with catheter no $>1$ & $0(0.00 \%)$ & $4(10.00 \%)$ & 0.888 \\
\hline Procalcitonin (ng/mL; av., SD) & $29.91(15.39)$ & $32.00(70.89)$ & 0.108 \\
\hline CRP (C-reactive protein) (mg/L; av., SD) & $2.6(1.72)$ & $1.38(1.11)$ & 0.141 \\
\hline Leucocytes (U/L; av., SD) & $14.20(5.23)$ & $10.63(5.89)$ & 0.056 \\
\hline Haemoglobin (mg/dl; av., SD) & $9.31(1.98)$ & $10.09(1.44)$ & 0.316 \\
\hline Platelets (K/L; av., SD.) & $104(56)$ & I7| (78) & 0.015 \\
\hline Leucocytes/platelets ratio (av., SD) & $0.16(0.09)$ & $0.08(0.06)$ & 0.002 \\
\hline
\end{tabular}

COPD: chronic obstructive pulmonary disease; NYHA: New York Heart Association; CIED: cardiac implantable electronic devices 
Table 6. Risk factors of death of patients with catheter related infections

\begin{tabular}{|l|c|c|c|}
\hline Infection-related complications & OR & $95 \% \mathrm{Cl}$ & P \\
\hline Cardiac implants $^{\mathrm{a}}$ & 7.500 & $1.193-47.159$ & 0.027 \\
\hline hypotension & 7.500 & $1.193-47.159$ & 0.027 \\
\hline Leucocytosis & 1.089 & $0.962-1.233$ & 0.167 \\
\hline Platelets (PLT) & 0.153 & $0.027-0.869$ & 0.029 \\
\hline Leucocytes/platelets ratio & 1.165 & $1.024-1.326$ & 0.017 \\
\hline
\end{tabular}

apresence of CIED or biomaterial implanted to peripheral vessels; OR: odds ratio; $\mathrm{Cl}$ : confidence inteval

severe infection with hypotension, high leukocytosis, thrombocytopenia and a high ratio of leukocytes to platelets. Previous reports confirmed an unfavourable prognosis for cases of similar constellation of inflammatory parameters in dialyzed patients [11, 13, 29-32].

The present study also demonstrated that the presence of artificial devices and biomaterials increase mortality risk in the course of infection in patients dialyzed with permanent catheters $(\mathrm{OR}=7.5 ; 95 \% \mathrm{Cl}$ : I. 193-47.159; $P=0,027)$. Likewise, previous reports showed a negative effect of the presence of the cardiac implantable electronic devices on the development of infectious complications. Endocarditis, bacteremia and sepsis were often complications observed in this population, especially in patients dialyzed with permanent catheters [17, 23, 25, 26, 33]. Infectious complications caused by a dialysis catheter are a serious problem. Although the study was conducted on a small group and was retrospective, it showed certain risk factors for death and poor prognosis in this burdened group, similar to those of other researchers. The situation requires further observation and conducting a prospective study, preferably on a larger group of patients, in order to obtain better results.

\section{Study limitations}

This study is a retrospective analysis and it was conducted on the basis of selected data made available by the National Health Fund. Detailed clinical data concerning infection-related complications were available for 47 patients only.

\section{Conclusions}

Infections in patients dialyzed with permanent catheters are a common, serious complication. The specific risk factors of catheter-related infections include younger age, coronary artery disease and heart failure. Mortality of patients with infectious complications is very high, but comparable to the survival of all dialyzed by the permanent catheter. A higher mortality rate among patients with catheter-related infection increase with the presence of additional intravascular and intracardiac implanted materials and a severe course of infection with hypotension, thrombocytopenia and a high leucocytes/platelets ratio.

\section{Conflict of interest}

None.

\section{References:}

I. Brala M, Kamiński R. Trudnowski S. et al. Long-term complications after implantation of catheters for hemodialysis. Geriatrics. 20I4; 8: I-5.

2. Załuska W, Klinger M, Kusztal M, et al. Recommendations of the Working Group of the Polish Society of Nephrology for the criteria of quality treatment in dialysis patients with end-stage renal disease. Nefrol Dial Pol . 20I5; 919 : 6-II.

3. Weyde W, Krajewska M, Klinger M. Vascular access for hemodialysis. Polish Nefrol Forum. 2008; I(3): I19-126.

4. Polkinghorne KR, McDonald SP, Atkins RC, et al. Vascular access and all-cause mortality: a propensity score analysis. J Am Soc Nephrol. 2004; 15(2): 477-486, doi: 10.1097/0I. asn.0000109668.05 157.05, indexed in Pubmed: 14747396.

5. O'Grady NP, Alexander M, Burns LA, et al. Healthcare Infection Control Practices Advisory Committee (HICPAC). Guidelines for the prevention of intravascular catheter-related infections. Clin Infect Dis. 201 I; 52(9): el62-el 93, doi: 10.1093/cid/cir257, indexed in Pubmed: 21460264.

6. Maczyńska B, Przondo-Mordarska A. Bloodstream infections related to venous access. Zakażenia . 20 I ; I I(4): I07-II6.

7. National Healthcare Safety Network (NHSN, Report, CDC). https://www.cdc.gov/nhsn/datastat/index.html.

8. Lin KY, Cheng A, Chang YC, et al. Central line-associated bloodstream infections among critically-ill patients in the era of bundle care. J Microbiol Immunol Infect. 2017; 50(3): 339-348, doi: 10.1016/j.jmii.2015.07.00I, indexed in Pubmed: 26316008.

9. Haddadin Y, Regunath H. Central Line Associated Blood Stream Infections (CLABSI). StatPearls [Internet]. Treasure Island (FL): StatPearls Publishing; 2019.

10. El Minschawy. Evaluation of vascular access complications in acute and chronic hemodialysis; The Journal of Vascular Access. 2004; 5(2): 76-82.

II. Fysaraki M, Samonis G, Valachis A, et al. Incidence, clinical, microbiological features and outcome of bloodstream infec- 
tions in patients undergoing hemodialysis. Int J Med Sci. 2013; 10(12): 1632-1638, doi: 10.7150/ijms.6710, indexed in Pubmed: 24151435 .

12. Knezevic V, Durdević-Micković T, Bozić D. Risk factors for catheter-related infections in patients on hemodialysis. Vojnosanit Pregl . 2018; 75(2): 159-166, doi: 10.2298/VSPI60205332.

13. Delistefani F, Wallbach M, Müller GA, et al. Risk factors for catheter-related infections in patients receiving permanent dialysis catheter. BMC Nephrol. 2019; 20(I): 199, doi: 10.1 186/s |2882019-1392-0, indexed in Pubmed: 31151433.

14. Silva TNV, Mendes ML, Abrão JMG, et al. Successful prevention of tunneled central catheter infection by antibiotic lock therapy using cefazolin and gentamicin. Int Urol Nephrol. 2013; 45(5): |405-|4|3, doi: 10.1007/s | |255-0|2-0339-I, indexed in Pubmed: 23269457.

15. Thompson S, Wiebe N, Klarenbach S, et al. Alberta Kidney Disease Network. Catheter-related blood stream infections in hemodialysis patients: a prospective cohort study. BMC Nephrol. 2017; I8(I): 357, doi: 10.1 I86/s 12882-017-0773-5, indexed in Pubmed: 29221439.

16. Lemaire $\mathrm{X}$, Morena M, Leray-Moragués $\mathrm{H}$, et al. Analysis of risk factors for catheter-related bacteremia in 2000 permanent dual catheters for hemodialysis. Blood Purif. 2009; 28(I): 21-28, doi: 10.1159/000210034, indexed in Pubmed: 19325236.

17. Maki DG, Kluger DM, Crnich CJ. The risk of bloodstream infection in adults with different intravascular devices: a systematic review of 200 published prospective studies. Mayo Clin Proc. 2006; 8I(9): II59-117I, doi: 10.4065/81.9.1159, indexed in Pubmed: 16970212.

18. Murea M, James KM, Russell GB, et al. Risk of catheter-related bloodstream infection in elderly patients on hemodialysis. Clin J Am Soc Nephrol. 2014; 9(4): 764-770, doi: 10.2215/ CJN.077107I3, indexed in Pubmed: 24651074.

19. Milaniuk A, Stefanowicz J. Central venous catheter and the risk of catheter associated bloodstream infection in young oncological patient. Ann Acad Med Gedan. 2015; 45: 19-33.

20. Camins BC. Prevention and treatment of hemodialysis-related bloodstream infections. Semin Dial. 2013; 26(4): 476-48I, doi: 10.1 I I I/sdi. 121 17, indexed in Pubmed: 23859190.

21. Resić H, Ajanović S, Kukavica N, et al. [Tunneled catheter infections in patients on hemodialysis--one center experience]. Acta Med Croatica. 2012; 66 Suppl 2: 17-21, indexed in Pubmed: 23513412.

22. Maczyńska B, Smutnicka D, Przondo-Mordarska A. Biofilm formation by clinical Klebsiella strains expressing various types of adhesins on chemically different catheters. Adv Clin Exp Med. 2010; 19(2): 95-104.
23. Lima JK, Lima SR, de Lima AL, et al. Double-lumen catheter in the right jugular vein induces two sub-endothelial abscesses in an unusual place, the transition between the superior vena cava and the right atrium: a case report. Int Arch Med. 2014; 7: 37, doi: 10.1 | 86/ I755-7682-7-37, indexed in Pubmed: 25। 0520.

24. Wolska K, Jakubczak A. Detection of Pseudomonas aeruginosa biofilm on medical biomaterials. Medycyna doświadczalna i mikrobiologia . 2003; 55(4): 37I-378.

25. Kusztal M, Nowak K. Cardiac implantable electronic device and vascular access: Strategies to overcome problems. J Vasc Access. 2018; 19(6): 52I-527, doi: 10.1177// I297298/876298।, indexed in Pubmed: 29552930.

26. Saad TF, Ahmed W, Davis K, et al. Cardiovascular implantable electronic devices in hemodialysis patients: prevalence and implications for arteriovenous hemodialysis access interventions. Semin Dial. 2015; 28(I): 94-100, doi: 10.1 III/sdi.12249, indexed in Pubmed: 24863543.

27. Lai NM, Chaiyakunapruk N, Lai NAn, et al. Catheter impregnation, coating or bonding for reducing central venous catheter-related infections in adults. Cochrane Database Syst Rev. 2016; 3: CD007878, doi: 10.1002/1465/858.CD007878.pub3, indexed in Pubmed: 26982376.

28. Bray BD, Boyd J, Daly C, et al. Scottish Renal Registry. Vascular access type and risk of mortality in a national prospective cohort of haemodialysis patients. QJM. 20 12; 105(I I): 1097-I I03, doi: 10.1093/qjmed/hcs |43, indexed in Pubmed: 22908320.

29. Yaprak M, Turan MN, Dayanan R, et al. Platelet-to-lymphocyte ratio predicts mortality better than neutrophil-to-lymphocyte ratio in hemodialysis patients. Int Urol Nephrol. 2016; 48(8): 1343-1348, doi: |0. 1007/s | |255-0|6-| 30 |-4, indexed in Pubmed: 27| | 8565.

30. Valencia VC, Cruz CO, Rodríguez OM, et al. Inflamación en hemodiálisis y su correlación con los índices neutrófilos/linfocitos y plaquetas/linfocitos. Nefrología. 2017; 37(5): 554-556, doi: 10.1016/j.nefro.2016.12.006.

31. Catabay C, Obi Y, Streja E, et al. Lymphocyte Cell Ratios and Mortality among Incident Hemodialysis Patients. Am J Nephrol. 2017; 46(5): 408-416, doi: 10.1159/000484177, indexed in Pubmed: 29130984.

32. Turkmen K, Erdur FM, Ozcicek F, et al. Platelet-to-lymphocyte ratio better predicts inflammation than neutrophil-to-lymphocyte ratio in end-stage renal disease patients. Hemodial Int. 2013; 17(3): 391-396, doi: 10.1 I I//hdi. 12040, indexed in Pubmed: 23522328.

33. Oun HA, Price AJ, Traynor JP. Infective endocarditis in patients on haemodialysis - possible strategies for prevention. Scott Med J. 2016; 6I(2): 97-102, doi: 10.1 I77/0036933016636289, indexed in Pubmed: 27334533. 